\title{
Maintaining Resilience in Today's Medical Environment: Personal Perspectives on Self-Care
}

\author{
Umakant Dave $\mathbb{D}^{\prime}$, Simon D Taylor-Robinson $\mathbb{D}^{2}$ \\ 'Department of Gastroenterology, Morriston Hospital, Swansea, Wales, SA6 6NL, UK; ${ }^{2}$ Department of Surgery and Cancer, Imperial College London, \\ St Mary's Hospital Campus, London, W2 INY, UK \\ Correspondence: Simon D Taylor-Robinson, Department of Surgery and Cancer, Imperial College London, St Mary's Hospital Campus, London, W2 \\ INY, UK, Tel +44203312 6254, Email str338333@gmail.com
}

Background: The practice of medicine is becoming increasingly more stressful, owing to technological development, increased expectations, infrastructure deficiencies, lack of resources and healthcare systems that are struggling to cope in the face of the COVID19 pandemic around the world.

Objective: In this article, we explore ways to reduce stress and improve resilience in the work place in order to enhance wellbeing in the medical profession, but also ultimately to protect patient safety.

Synopsis: We discuss attention to regular mealtimes, protected sleep and daily exercise, together with consideration of mindfulness, gratefulness, self-compassion, self-care and being part of supportive networks as ways to reduce stress.

Conclusion: While such techniques are not guaranteed to mitigate stress, psychology studies have shown that awareness of and attention to these components of a healthy lifestyle have the potential to reduce the adverse effects of increasing professional demands.

Keywords: mindfulness, burnout, self-care, self-compassion, wellbeing, gratefulness

Ignoring the cumulative stress load that may impact all healthcare professionals in the current COVID-19 era may lead to errors of clinical judgment, burnout, reduced team effectiveness, poor communication with colleagues and patients, early retirement from clinical practice, or chronic physical and mental health issues, substance abuse and suicide. Apart from harm to the individual, ultimately patients suffer too. An American College of Surgeons survey found a marked adverse relationship between major medical errors, a surgeon's mental quality of life, and all the three major domains of burnout: emotional exhaustion, "depersonalisation" (or detachment from the job) and a sense of low personal accomplishment or ineffectiveness. ${ }^{1}$ It should be noted that burnout is not technically the same as stress and cannot be cured by holidays or slowing down, although the terms are often confused. Recent findings do not support the view that burnout is first and foremost related to occupational-context factors and show that it is primarily accounted for by personality trait neuroticism. $^{2}$

Many healthcare professionals believe that it is circumstance and work environment that are the main factors in reduced wellbeing at work and they themselves are passive players. Some ignore personal responsibility or "ownership" of the problem and the development of resilience to these issues is often overlooked. ${ }^{3}$ Systematic review and metaanalysis by West et al substantiate that both individual-focused and structural or organisational interventions can reduce

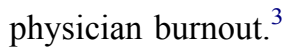

Rosenberg suggests that the development of resilience should be considered a "process of harnessing the resources we need to sustain well-being". ${ }^{4}$ Being in touch with strategies to prevent burnout, allows personal ownership of resilience and self-fulfilment. ${ }^{4}$ In this context, Cook-Cottone and Guyker have developed a very useful 33-item Mindful Self-Care Scale (MSCS) based on six areas: physical care, supportive relationship, mindful awareness, self-compassion and purpose, mindful relaxation and supportive structures. ${ }^{5}$ 
Based on our personal experience of working in the British National Health Service (NHS) (with over 60 years' combined experience), and review of literature, we suggest eight personal habits or skills that should be considered in improving doctors' wellbeing. This list is not exhaustive and there are other habits or skills that will improve doctors' wellbeing. We have selected the following eight habits or skills, based on our experience. We appreciate that not all the suggestions will suit everyone and may not fit into daily schedules due to other demands, but starting with one or two items and then building up slowly should provide a platform to build resilience.

1. Diet and nutrition: A lack of regular breaks and irregular meal times has a significant negative impact on doctors' personal wellness and professional performance. ${ }^{6}$ There is a strong relationship between nutrition and mental health in adults and this has been found to differ between depressed and anxious individuals. ${ }^{7}$ Taking regular meal breaks, eating healthily, especially with colleagues away from the clinical arena, rather than at a desk in front of a computer, promotes physical and mental wellbeing. ${ }^{7}$

2. Reappraisal of stress: When stress inevitably occurs, a greater understanding of stress management skills may be useful. Individuals who perceive that stress affects their health and report a large amount of stress have an increased risk of premature death, but individuals with high stress levels who do not perceive stress as harmful do not. ${ }^{8}$ This supports the idea that stress appraisal is critical in determining outcomes. We suggest that reappraisal can be considered by recognising physiological responses to stress as a positive phenomenon, helping to rise to the challenge, rather than a negative one in response to a threatening situation.

3. Sleep: Cognitively and emotionally, improved sleep leads to dose-dependent improvement in (1) the ability to focus and sustain attention, (2) working memory and long-term memory, (3) learning of complex skills, (4) the inability to discriminate the value of rewards with increased risk-taking and impulsivity, and (5) negative emotional reactivity and expression, mediated in large part by the impairment of the prefrontal cortical control over other areas of the brain. ${ }^{9} \mathrm{We}$ suggest making a personal commitment to sleep 7 to 9 hours a night, whenever possible and to work around constraints: on-call activity, nightshifts, examinations and other acute demands. When deprived, owing to such demands, sleep time should be caught up as soon as is possible to maintain a healthy work-life balance.

4. Exercise: While the effect of exercise on physical health is well recognised, exercise also improves cognitive and emotional health. There is a growing body of evidence that shows the positive effects of exercise on mood state, such as anxiety, stress and depression through physiological, biochemical and psychological mechanisms. ${ }^{10}$ Increasing physical activities in daily lives does not need to come as a significant time or financial burden. Incorporating more walking and being active at work, when travelling to work and when at home can provide many benefits of exercise without additional demands.

5. Mindfulness: Evidence has shown strong benefits of mindfulness/meditation practice to wellbeing, resilience and adaptation to stressful situations. Benefit from meditation can be derived without an extensive time commitment. ESRT (Enhanced Stress Resilience Training) - a mindfulness-based training programme has shown potential benefits to wellbeing and executive function in the time-compressed and high-stake surgical training environment. ${ }^{11}$ As little as 13 min a day, if practiced daily, is beneficial. ${ }^{12}$ It is possible to use a meditation app for even a short meditation practice.

6. Gratefulness: Gratitude is the appreciation of what is valuable and meaningful to oneself and represents a general state of thankfulness and/or appreciation. Low gratitude states are related to impaired clinical functioning, whereas increased gratitude predicts wellbeing in psychological studies. ${ }^{13}$ The interventions to enhance gratitude can be classed into three categories: (a) daily listing of things for which to be grateful (journaling), (b) grateful contemplation (meditation), and (c) behavioral expressions of gratitude (writing or personally expressing them).

7. Self-compassion and self-care: Self-compassion in a simple way is "to replace harsh internal critics by a caring friend". A mindful self-compassion program in a randomised controlled trial was also effective at increasing compassion for others, and enhancing other aspects of wellbeing. Benefits were present a year after completing the program. ${ }^{14}$ Another important aspect of self-care is to say "no", when additional demands are placed that are detrimental.

8. Being part of supportive networks: Loneliness influences virtually every aspect of life. Enhanced social support, social skills development or increased opportunities for social interaction does provide some benefit, but a dedicated, facilitated program where a group of 6-10 physicians meet twice a month was shown to enhance engagement and reduce 
some domains of burnout. ${ }^{15}$ Volunteering, mentoring younger colleagues and joining hobby groups also provide opportunities to develop supportive network.

\section{Conclusions}

While there are no cast-iron remedies for stress in medical practice, considering at least some of the ideas we have suggested may allow some resilience to be developed in what is undoubtedly an increasingly complex profession. This is particularly important in the ongoing COVID-19 pandemic, which adds additional anxieties, related to healthcare systems being overburdened, under-resourced and understaffed.

\section{Acknowledgments}

UD is grateful to Prof Rebecca Crane and the Centre for Mindfulness training team (Bangor University, Gwynedd, UK) for mindfulness training and Dr Carter Lebares and UCSF Centre for Mindfulness in Surgery team (UCSF, California, USA) for ESRT training. SDT-R is grateful to the UK National Institute for Healthcare Research (NIHR) Biomedical Facility at Imperial College London for infrastructure support and to the Wellcome Institutional Strategic Support Fund at Imperial College for fostering research collaborations. The authors thank Professor C. Wendy Spearman from the University of Cape Town, South Africa for useful discussions; Professor Peter Olupot-Olupot from Busitema University, Uganda for philosophical comments on the manuscript and Professor Babatunde L. Salako, Director General of the Nigerian Institute of Medical Research (NIMR), Lagos, Nigeria for expert guidance.

\section{Disclosure}

The authors report no conflicts of interest in this work.

\section{References}

1. Shanafelt TD, Balch CM, Bechamps G, et al. Burnout and medical errors among American surgeons. Ann Surg. 2010;251:995-1000. doi:10.1097/ SLA.0b013e3181bfdab3

2. Bianchi R, Manzano-García G, Rolland JP. Is burnout primarily linked to work-situated factors? A relative weight analytic study. Front Psychol. 2021;13(11):623912. doi:10.3389/fpsyg.2020.623912

3. West CP, Dyrbye LN, Erwin PJ, Shanafelt TD. Interventions to prevent and reduce physician burnout: a systematic review and meta-analysis. Lancet. 2016;388(10057):2272-2281. doi:10.1016/S0140-6736(16)31279-X

4. Rosenberg AR. Seeking professional resilience. Pediatrics. 2018;141(3). doi:10.1542/peds.2017-2388

5. Cook-Cottone CP, Guyker WM. The development and validation of the mindful self-care scale (MSCS): an assessment of practices that support positive embodiment. Mindfulness. 2018;9(1):161-175. doi:10.1007/s12671-017-0759-1

6. Lemaire JB, Wallace JE, Dinsmore K, Roberts D. Food for thought: an exploratory study of how physicians experience poor workplace nutrition. Nutr J. 2011;10(1):1-8. doi:10.1186/1475-2891-10-18

7. Jacka FN. Nutritional psychiatry: where to next? EBioMedicine. 2017;17:24-29. doi:10.1016/j.ebiom.2017.02.020

8. Keller A, Litzelman K, Wisk LE, et al. Does the perception that stress affects health matter? The association with health and mortality. Health Psychol. 2012;31(5):677. doi:10.1037/a0026743

9. Krause AJ, Simon EB, Mander BA, et al. The sleep-deprived human brain. Nat Rev Neurosci. 2017;18(7):404-418. doi:10.1038/nrn.2017.55

10. Mikkelsen K, Stojanovska L, Polenakovic M, Bosevski M, Apostolopoulos V. Exercise and mental health. Maturitas. 2017;106:48-56. doi:10.1016/j.maturitas.2017.09.003

11. Lebares CC, Guvva EV, Olaru M, et al. Efficacy of mindfulness-based cognitive training in surgery: additional analysis of the mindful surgeon pilot randomized clinical trial. JAMA Network Open. 2019;2(5):e194108. doi:10.1001/jamanetworkopen.2019.4108

12. Basso JC, McHale A, Ende V, Oberlin DJ, Suzuki WA. Brief, daily meditation enhances attention, memory, mood, and emotional regulation in non-experienced meditators. Behav Brain Res. 2019;356:208-220. doi:10.1016/j.bbr.2018.08.023

13. Wood AM, Froh JJ, Geraghty AW. Gratitude and well-being: a review and theoretical integration. Clin Psychol Rev. 2010;30(7):890-905. doi:10.1016/j.cpr.2010.03.005

14. Neff KD, Germer CK. A pilot study and randomized controlled trial of the mindful self-compassion program. J Clin Psychol. 2013;69(1):28-44. doi: $10.1002 /$ jclp. 21923

15. West C. The mayo clinic program on physician well-being: studying solutions to physician burnout. In: SGIM Forum. Vol. 40. No. 4. Mayo Clinic; 2017:1-2. 


\section{Publish your work in this journal}

The International Journal of General Medicine is an international, peer-reviewed open-access journal that focuses on general and internal medicine, pathogenesis, epidemiology, diagnosis, monitoring and treatment protocols. The journal is characterized by the rapid reporting of reviews, original research and clinical studies across all disease areas. The manuscript management system is completely online and includes a very quick and fair peer-review system, which is all easy to use. Visit http://www.dovepress.com/testimonials.php to read real quotes from published authors.

Submit your manuscript here: https://www.dovepress.com/international-journal-of-general-medicine-journal 